\title{
Association Between Inflammatory Cytokines and Immune- Checkpoint Molecule in Rheumatoid Arthritis
}

\section{Haruki Matsumoto}

Fukushima Kenritsu Ika Daigaku

\section{Yuya Fujita}

Fukushima Kenritsu Ika Daigaku

\section{Tomoyuki Asano}

Fukushima Kenritsu Ika Daigaku

\section{Naoki Matsuoka}

Fukushima Kenritsu Ika Daigaku

Jumpei Temmoku

Fukushima Kenritsu Ika Daigaku

\section{Shuzo Sato}

Fukushima Kenritsu Ika Daigaku

\section{Makiko Yashiro-Furuya}

Fukushima Kenritsu Ika Daigaku

\section{Kohei Yokose}

Fukushima Kenritsu Ika Daigaku

\section{Shuhei Yoshida}

Fukushima Kenritsu Ika Daigaku

\section{Eiji Suzuki}

Fukushima Kenritsu Ika Daigaku

Toru Yago

Fukushima Kenritsu Ika Daigaku

\section{Hiroshi Watanabe}

Fukushima Kenritsu Ika Daigaku

Atsushi Kawakami

Fukushima Kenritsu Ika Daigaku

Kiyoshi Migita ( $\nabla$ migita@fmu.ac.jp )

Fukushima Medical University School of Medicine

\section{Research article}

Keywords: anti-citrullinated peptide antibodies, checkpoint molecules, cytokines, galectin-9, interleukin-6, tumor necrosis factor-a, rheumatoid arthritis

Posted Date: June 4th, 2021

DOI: https://doi.org/10.21203/rs.3.rs-546264/v1

License: (c) (i) This work is licensed under a Creative Commons Attribution 4.0 International License. Read Full License 
Version of Record: A version of this preprint was published at PLOS ONE on November 18th, 2021. See the published version at https://doi.org/10.1371/journal.pone.0260254. 


\section{Abstract}

\section{Background}

Rheumatoid arthritis (RA) is a heterogeneous inflammatory disease. Both anti-citrullinated peptide antibodies (ACPA) and inflammatory cytokines play an important role in the development of RA. The aim of this study was to investigate the association between inflammatory cytokines and co-inhibitory checkpoint molecules in patients with RA.

\section{Methods}

One hundred and thirty-two Japanese patients with established RA were enrolled. Serum levels of interleukin-6 (IL-6) and tumor necrosis factor- $a$ (TNF- $a$ ) were determined by ELISA. Patients were stratified into two groups based on ACPA titers: low-medium ACPA (ACPA $<200 \mathrm{U} / \mathrm{mL}$ ) and high ACPA (ACPA $\geq 200 \mathrm{U} / \mathrm{mL}$ ). Serum levels of cytokines or co-inhibitory checkpoint molecules were compared according to the status of ACPA titers and joint progression stage.

\section{Results}

Baseline serum levels of TNF- $\alpha$ and IL- 6 were significantly elevated in RA patients; however, the two cytokines showed no correlation with each other. Serum levels of IL-6 or TNF-a showed a significant correlation with DAS28-CRP, independent of ACPA status. Although serum levels of soluble T-cell immunoglobulin and mucin-domain containing-3 (sTIM-3) were elevated in RA patients, significant correlation of sTIM-3 with IL- 6 or TNF-a was only observed in RA patients with low-medium levels of ACPA titers ( $<200 \mathrm{U} / \mathrm{mL}$ ). Serum levels of IL-6 and TNF-a were significantly correlated with elevated levels of galectin-9 (Gal-9) independent of ACPA status. Whereas, a significant correlation between IL- 6 and Gal-9 was observed only in RA patients without advanced joint damage (Stage I). Conversely, significant correlation between TNF-a and Gal-9 was observed only in RA patients with advanced joint damage (Stage II-IV).

\section{Conclusions}

RA patients may be differentiated based on the interplay between serum cytokines and co-inhibitory molecules. RA patients with minimal joint damage (Stage I) appear to show positive correlation between Gal-9 and IL-6. Conversely, RA patients with advanced joint damage (Stage II-IV) appear to show positive correlation between Gal-9 and TNF-a. Serum levels of cytokines and immune-checkpoint molecules may be useful markers for predicting the immune phenotype and further personalized treatment of RA.

\section{Background}

Rheumatoid arthritis (RA) is an autoimmune inflammatory disease that results in joint destruction and disability [1]. RA is characterized by the production of auto-antibodies and cytokine-mediated synovial or systemic inflammation [2]. Cytokine networks play an important role in the pathogenesis of RA [3]. Sustained production of proinflammatory cytokines was shown to correlate with rheumatoid inflammation [4]. Previous studies have shown that the manipulation of serum cytokine levels is the main mechanism of action of biologics or targeted synthetic disease-modifying antirheumatic drugs (tsDMARDs) for RA [5, 6]. Increased levels of cytokines, including tumor necrosis factor-a (TNF-a) and interleukin-6 (IL-6), reflect the rheumatoid synovial inflammation and have been shown to be associated with RA disease activity or response to anti-cytokine therapy $[3,4,7,8]$. However, the association between circulating cytokines levels and RA disease phenotype is not well characterized. TNF-a plays a key role in the pathogenesis of RA [3]. TNF-a affects different cell types and is produced mainly by monocytes, macrophages, and T cells $[9,10]$. IL-6 is another cytokine which is considered as disease driving cytokine in RA [11]. In RA, IL-6 is increased in synovium and blood, and its level correlates with clinical disease activity and joint damage $[7,12]$.

Anti-citrullinated peptide antibodies (ACPA) are useful for the diagnosis of RA and have been shown to be associated with progression of joint destruction or therapeutic response in patients with RA [13]. However, the interactions between ACPA status and proinflammatory cytokines during RA disease progression are yet to be fully clarified [14]. Rheumatoid synovitis and articular damage are mediated through several cell types, including T cells, B cells, monocytes, and osteoclasts [15]. Immune- 
checkpoint molecules may play a role in the interaction between these immune cells and their activation [16, 17]. We hypothesized that immune-checkpoint molecules are possible modulators of immunopathology in RA through their interactions with cytokines. In this study we investigated the influence of these combined biomarkers, including autoantibodies, cytokines, and immune-checkpoint molecules, on the disease activity or progression of RA.

\section{Methods}

\section{Patients}

This observational single-center study included 132 consecutive RA patients. Patients were enrolled between February 2012 and June 2020, with follow-up ending in June 2020. We retrospectively reviewed the records of these RA patients. All patients were treated in Department of Rheumatology, Fukushima Medical School from June 2009 to June 2020. All the patients met the 2010 ACR/EULAR classification criteria for the disease [18]. Probable RA or overlap syndromes were excluded.

The following clinico-demographic data were collected from the Medical Records Unit at Fukushima University Hospital: age, age at onset of RA, gender, Disease Activity Score-28 for Rheumatoid Arthritis with C-reactive protein (CRP) (DAS28-CRP) score. As controls, 19 healthy subjects (7 males, 12 females, median age 40 years, interquartile range [IQR]; 33-42 years) were included. This study was conducted in accordance with the principles of the Declaration of Helsinki. Ethical approval for this study (No.2019097) was provided by the Ethics Committee of Fukushima Medical University.

\section{Measurement of clinical disease activity}

All patients underwent clinical assessment at baseline, including 28-joint swollen and tender joint counts (28-SJC and 28-TJC, respectively), physician and patient global assessment with visual analogue scales $(0-100 \mathrm{~mm})$ and $\mathrm{CRP}(\mathrm{mg} / \mathrm{dL})$. The composite disease activity indices were subsequently calculated: DAS28-CRP. The patients' anti-CCP antibodies were analyzed using commercially available second-generation chemiluminescent enzyme immunoassay kits (STACIA® MEBLuxTM CCP test, Medical and Biological Laboratories, Aichi, Japan) according to the manufacturer's instructions. The results were reported qualitatively where negative or positive for anti-CCP antibody was defined as $<4.5 \mathrm{U} / \mathrm{ml}$ or $\geq 4.5 \mathrm{U} / \mathrm{ml}$, respectively. Matrix metalloproteinase-3 (MMP-3) was measured as a biomarker of joint damage. Radiographs were taken of both hands of each patient. Two rheumatologists, blinded to the patient's identify and functional status, independently graded each hand radiographs and assigned as Steinbrocker radiographic stage [19]. Stage I is the early RA stage which do not occur joint damage. In Stage II, bone erosion is seen on hand radiographs, but no joint deformity. In Stage III, joint deformity is observed and, in Stage IV, bone ankylosis observed.

\section{ELISA methods}

Serum concentrations of Galectin-9, sTIM-3, IL-6 (No. HS600C) and TNF-a (No. HSTA00E) were measured using enzyme-linked immnunosorbent assay kit (R\&D Systems, Minneapolis, MN, USA) according to the manufacturer's instruction.

\section{Statistical analysis}

Results were non-normally distributed and are presented throughout the manuscript with median and interquartile range [IQR], and were compared by the Mann-Whitney $U$ test. Correlations between continuous variables were analyzed by the Spearman's rank correlation test. All data entry and statistical analyses were performed using SPSS Statistics version 22.0 (IBM, Armonk, NY). In all the analyses, a 2 - tailed $p<0.05$ was considered statistically significant.

\section{Results}

\section{Patient characteristics}

Table 1 shows the demographic and clinical data of the 132 RA patients (35 males and 97 females) enrolled in this study. The median age of patients was 66 (56-73) years. The average course of RA disease was 7 (2-11) years and average DAS28 (CRP) level was 2.5 (1.8-3.2). Fifty-eight (43.9\%) patients had moderate or severe disease activity. The proportion of ACPA-negative (<

Page 4/18 
$4.5 \mathrm{U} / \mathrm{mL}$ ) patients was $11 \%$ (14 of 132). The proportion of patients with elevated ACPA titers ( $\geq 200 \mathrm{U} / \mathrm{mL})$ was $33 \%$ (43 of 132). The median [IQR] level of serum MMP was $119.5(67.6-228.8) \mathrm{ng} / \mathrm{mL}$.

\section{Serum levels of cytokines}

To assess the cytokine profiles corresponded to RA phenotype, we measured the serum levels of IL-6 and TNF-a in RA patients. Figure 1 shows the serum levels of IL-6 in RA patients and healthy subjects $(n=19)$. Serum levels of IL- 6 were significantly higher in RA patients (median [IQR], 31.5 [12.1-41.5] pg/mL). Although serum TNF-a level was not detected in HC, patients with RA showed elevated serum levels of TNF-a $(11.1 \mathrm{mg} / \mathrm{mL}$ [IQR; 4.1-21.1] ng/mL). Figure 2 shows the relationship between serum levels of IL- 6 and TNF-a in RA patients. Interestingly, circulating levels of IL- 6 and TNF-a were elevated independent of each other; a majority of RA patients presented with high level of IL-6 plus low TNF-a level or high level of TNF-a plus low IL-6 level. Only few RA patients had high levels of both cytokines.

\section{Serum levels of co-inhibitory checkpoint molecules (Fig. 3A, 3B)}

Consistent with previous reports [20], serum levels of galectin-9 (Gal-9) in RA patients (median [IQR], 7.84 [5.69-10.38] pg/mL) were significantly higher than those in HC (median [IQR]; 3.84 [3.22-4.56] pg/mL). Similarly, serum levels of sTIM-3 in RA patients (median [IQR], 2,628 [1,891-3,664] pg/mL) were significantly higher than those in HC (median [IQR], 871 [644-2,059] $\mathrm{pg} / \mathrm{mL})$.

\section{Correlation of serum levels of cytokines with biomarkers in RA patients}

Table 2 shows the correlation of baseline serum levels of cytokines biomarkers. There was a significant positive correlation between cytokines (IL-6 or TNF-a) and co-inhibitory checkpoint molecules (Gal-9 and sTIM-3). However, there was no significant correlation between serum levels of cytokines (IL-6 or TNF-a) and ACPA titers.

In our previous study, we found that the association between serum levels of checkpoint molecules and ACPA was modulated by the status of ACPA titers $[20,21]$. The cutoff value of ACPA titer $(200 \mathrm{U} / \mathrm{mL})$ was determined according to the ability to extract the strongest correlation between checkpoint molecules and ACPA titer. We investigated the correlation between circulating cytokines and clinical parameters after disaggregating RA patients into two groups, based on the presence or absence of high ACPA titers $(\geq 200 \mathrm{U} / \mathrm{mL}$ ). As shown in Fig. 4, there were significant correlations between serum levels of cytokines (IL-6 or TNF-a) and RA disease activity (DAS28-CRP), and these correlations were not modulated by the high status of ACPA titer ( $\geq 200 \mathrm{U} / \mathrm{mL}$ ). Serum levels of IL-6 or TNF-a showed a significant correlation with Gal-9 independent of the ACPA status (Fig. 5). As shown in Fig. 6 , there were significant correlations between serum levels of cytokines (IL-6 or TNF-a) and STIM-3 in RA patients with low-medium levels of ACPA titers ( $<200 \mathrm{U} / \mathrm{mL}$ ). However, there was no significant correlation between serum levels of cytokines (IL-6 or TNFa) and sTIM-3 under the high status of ACPA titers $(\geq 200 \mathrm{IU} / \mathrm{mL})$.

\section{Relationship between cytokines and Gal-9 according to the joint destruction stage}

As shown in Fig. 7, serum levels of Gal-9 were significantly higher in RA patients with advanced joint damage (stage II-IV) compared to those without advanced joint damage (Stage I). We hypothesized that the elevated levels of Gal-9 in RA patients with advanced joint damage were linked with serum levels of cytokines. We compared the serum levels of cytokines between RA patients with or without advanced rheumatoid joint damage (Stage I versus Stage II-IV). As known in Fig. 8A, serum levels of TNF-a in RA patients with advanced joint damage (Stage II-IV) were significantly higher than those in patients without advanced joint damage (Stage I). Similarly, serum levels of IL-6 in RA patients with advanced joint damage were higher than those in patients without advanced joint damage; however, the between-group difference in this respect was not statistically significant $(p=0.1733$, Fig. 8B).

RA patients with advanced joint damage (Stage II-IV) showed elevated serum levels of Gal-9. Therefore, we assessed the correlation between cytokines and Gal-9 under the differential rheumatoid joint damage stage. As known in Fig. 9A, RA patients without advanced joint damage showed a positive correlation between IL-6 and Gal-9. Conversely, there was a significant 
correlation between TNF-a and Gal-9 (Fig. 9B) in RA patients with advanced rheumatoid joint damage (Stage II-IV). This positive correlation between TNF-a and Gal-9 was more markedly observed (Fig. 10) in RA patients with high ACPA titers ( $\geq 200 \mathrm{IU} / \mathrm{mL}$ ).

\section{Discussion}

Dysregulated cytokine production plays an important role in the progression of RA [4]. Given the complexity and heterogeneous nature of RA, it is unlikely that a single cytokine may explain the pathophysiology of RA [22]. Among these cytokines, the interplay between TNF- $a$ and IL- 6 is known to play a significant role in the inflammatory processes in RA $[3,4,7,8,23]$. Our results indicated the differential regulation of serum levels of TNF-a and IL-6 in patients with established RA. Serum concentrations of TNF-a were relatively low for determination by detection methods contributing to the conflicting outcomes of investigations using RA patients' sera [22]. In this context, we determined the serum TNF-a concentrations using high-sensitive ELISA method. Our data revealed that majority of RA patients presented with low or marginal levels of serum TNF-a levels, however, circulating TNF-a was detectable in a few patients with RA. In the sub-group of RA patients with low serum levels of TNF-a, IL-6 was randomly distributed and be correlated with rheumatoid inflammatory markers such as CRP or MMP-3. Although there was no significant association between ACPA titers and circulating TNF- $a$ or IL- 6 levels, our data demonstrated the associations of these cytokines and co-inhibitory checkpoint molecules under particular ACPA status.

Serum Gal-9 levels were correlated with TNF- $a$ and IL-6, independent of the ACPA titer status. However, elevated levels of sTIM-3 showed positive correlations with these cytokine only in RA patients without high titer of ACPA $(<200 \mathrm{U} / \mathrm{mL})$. Shedding of TIM-3 is found LPS-activated CD14区 monocytes or TIM-3 expressing T cell in patients with GVHD after hematopoietic cell transplantation [24, 25]. TIM-3 is a co-inhibitory receptor that is expressed on T cells or innate immune cells, where it has been shown to suppress their immune responses [26]. TIM-3 expression on CD4囚 and CD8 T cells in peripheral blood or synovial fluid was shown to be increased in RA patients [27]. Furthermore, the percentage of TIM-3 expressing CD $4 \llbracket$ and CD8 $\mathrm{T}$ cells was negatively correlated with RA disease activity [28]. It was also demonstrated that the expression levels of TIM-3 on T cells was also inversely correlated with plasma TNF levels in RA patients [28]. Taken together, our data suggest that TIM-3 shedding process can be differentially regulated by ACPA status and serum levels of sTIM-3 could be linked with the elevated levels of inflammatory cytokines in RA patients without high titers of ACPA $(<200 \mathrm{U} / \mathrm{mL})$.

Additionally, we found that the correlation between Gal-9 and inflammatory cytokines was modulated by the rheumatoid joint damage stage. Strong association of Gal-9 with circulating TNF-a, but not with IL-6, was demonstrated in RA patients with advanced joint damage (Stage II-IV). This tendency was more dominant in RA patients with high titers of ACPA ( $\geq 200 \mathrm{IU} / \mathrm{mL}$ ). Conversely, serum levels of Gal-9 showed a stronger correlation with IL-6 in RA patients without advanced joint damage (Stage I). These findings suggest that the interaction between IL- 6 and Gal-9 may be involved in rheumatoid inflammation in the early stage of RA. In contrast, interaction between TNF- $\alpha$ and Gal-9 may be involved in RA progression in advanced stages of joint destruction. The dual role of Gal-9, in correlating with inflammatory cytokines or ACPA titers may define the hierarchical position of RA phenotype or progression. These data suggest that the interplay between inflammatory cytokines and checkpoint molecules may differentially contribute to the rheumatoid inflammatory and articular destruction processes.

Gal-9 and these inflammatory cytokines seem to be upregulated during rheumatoid inflammation [29, 30]. However, the mechanism by which these molecules are regulated under the inflammatory or autoimmune conditions in various RA patients is not understood. Circulating Gal-9 could be a useful biomarker to monitor disease activity and facilitate personalized treatment [31]. Gal-9 is anti-inflammatory as suggested in RA model mice, CIA, in which Gal-9 injection suppressed osteoclasto genesis through the Gal-9/TIM-3 pathway [32]. Conversely, in RA patients, decreased Gal-9/TIM-3 signaling has been observed since the expression levels of TIM-3 on CD4 ${ }^{+} \mathrm{T}$ cells were lower compared to those from healthy controls [33-35]. Although its function is not fully elucidated, Gal-9 is a potent immune regulator and modulates rheumatoid inflammation and joint destruction [29].

TNF-a was shown to induce the secretion of Gal-9 by mesenchymal stem cells in vitro [36]. Conversely, TNF-a downregulated the surface expressions of TIM-3 on T cells probably by shedding mechanism [24]. Although the expression of TIM-3 on immune cells were not investigated in our study, the co-inhibitory Gal-9/TIM-3 pathways can be downregulated by decoy function of circulating sTIM-3. Gal-9 seems to be reciprocally upregulated to regulate the rheumatoid inflammation; however, sTIM-3, which 
is elevated in RA patients, can competitive inhibit this co-inhibitory Gal-9/TIM-3 pathway. Further studies are required to elucidate the mechanism by which these cytokines and immune-checkpoint molecules co-modulate the rheumatoid inflammatory processes.

Several potential limitations of this study should be considered while interpreting the results. First, the patient population was relatively small. A larger study is required to provide more definitive evidence. Second, all patients with RA and healthy individuals in this study were Japanese; additional studies in other ethnic groups are required to verify these findings. Third, a majority of the patients were already undergoing treatment; therefore, our findings may not be generalizable to untreated RA patients. Finally, future studies should examine the longitudinal changes in serum Gal-9, sTIM-3, IL-6, and TNF-a levels in patients with RA and assess their clinical course.

\section{Conclusions}

Our data provide new insights into the significance of the measurement of serum levels of IL- 6 and TNF- $a$ in RA. In RA patients, elevated levels of TNF- $a$ and IL- 6 showed a correlation with co-inhibitory molecules, Gal-9 or sTIM-3 under particular ACPA status and RA joint progression stages. Our data suggest that inflammatory cytokines and co-inhibitory checkpoint molecules may interact and reflect the rheumatoid articular inflammation or destruction. Measurement of serum IL- 6 and TNF-a concentrations in combination with checkpoint molecules may help predict the phenotypic alternations of RA.

\section{Abbreviations}

ACPA=Anti-citrullinated peptide antibodies

DAS28=Disease Activity Score-28

DMARDs=disease-modifying antirheumatic drugs

$\mathrm{ESR}=$ erythrocyte sedimentation rate

Gal-9=Galectin-9

IL-6=interleukin-6 (IL-6)

MMP-3=matrix metalloproteinase-3

$\mathrm{RA}=$ rheumatoid arthritis

TIM-3=T-cell immunoglobulin and mucin-domain containing-3

TNF- $a=$ tumor necrosis factor- $a($ TNF- $a)$

\section{Declarations}

\section{Ethical Approval and Consent to participate}

Ethical approval for this study (No. 2019097) was provided by the Ethics Committee of Fukushima Medical University.

\section{Consent for publication}

Not applicable

\section{Availability of supporting data}

Not applicable 


\section{Competing interests}

KM has received research grants from Chugai, Pfizer, and AbbVie. Rest of the authors declares that they have no competing interests

\section{Funding}

The study was supported by the Japan Grant-in-Aid for Scientific Research(C 17K09981).

\section{Authors' contributions}

YF, TA, NM, JT, SS, HM, MF, KY, SY, ES, TY, HK, HW were involved in acquisition of clinical data and drafted manuscript. YF performed the statistical analysis. KM participated in the design of the study and drafted manuscript. All authors read and approved the final manuscript.

\section{Acknowledgements}

We are grateful to Ms Sachiyo Kanno for her technical assistance in this study.

\section{References}

1. Smolen JS, Aletaha D, McInnes IB. Rheumatoid arthritis. Lancet. 2016; 388(10055):2023-38.

2. McInnes IB, Schett G. The pathogenesis of rheumatoid arthritis. N Engl J Med. 2011;365:2205-19.

3. McInnes IB, Schett G. Cytokines in the pathogenesis of rheumatoid arthritis. Nat Rev Immunol. 2007;7:429-

4. XiaT, ZhengXF, Qian BH, Fang H, Wang JJ,ZhangLL, et al.Plasmainterleukin-37iselevatedinpatientswithrheumatoid arthritis: its correlation with disease activity and Th1/Th2/Th17-related DisMarkers.2015;795043.

5. Furst DE, Emery P. Rheumatoid arthritis pathophysiology: update on emerging cytokine and cytokine-associated cell targets. Rheumatology (Oxford). 2014;53(9):1560-9.

6. Smolen JS, Landewé RBM, Bijlsma JWJ, Burmester GR, Dougados M, Kerschbaumer A, et al. EULAR recommendations for the management of rheumatoid arthritis with synthetic and biological disease-modifying antirheumatic drugs: 2019 update. Ann Rheum Dis. 2020;79(6):685-99.

7. Madhok R, Crilly A, Watson J, Capell HA. Serum interleukin 6 levels in rheumatoid arthritis: correlations with clinical and laboratory indices of disease activity. Ann Rheum Dis. 1993;52(3):232-4.

8. Ogata A, Kato Y, Higa S, Yoshizaki K. IL-6 inhibitor for the treatment of rheumatoid arthritis: A comprehensive review. 2019;29(2):258-67.

9. Schett G. Review: Immune cells and mediators of inflammatory arthritis. Autoimmunity. 2008;41(3):224-9.

10. Kollias G, Douni E, Kassiotis G, Kontoyiannis D. On the role of tumor necrosis factor and receptors in models of multiorgan failure, rheumatoid arthritis, multiple sclerosis and inflammatory bowel disease. Immunol Rev. 1999;169:175-94.

11. Fonseca JE, Santos MJ, Canhão H, Choy E. Interleukin-6 as a key player in systemic inflammation and joint destruction. Autoimmun Rev. 2009;8(7):538-42.

12. Abdel Meguid MH, Hamad YH, Swilam RS, Barakat MS. Relation of interleukin-6 in rheumatoid arthritis patients to systemic bone loss and structural bone damage. Rheumatol Int. 2013;33(3):697-703.

13. Steffen U, Schett G, Bozec A. How Autoantibodies Regulate Osteoclast Induced Bone Loss in Rheumatoid Arthritis. Front Immunol. 2019;10:1483.

14. Floudas A, Canavan M, McGarry T, Mullan R, Nagpal S, Veale DJ, et al. ACPA Status Correlates with Differential Immune Profile in Patients with Rheumatoid Arthritis. Cells. 2021;10(3):647.

15. Fang Q, Zhou C, Nandakumar KS. Molecular and cellular pathways contributing to joint damage in rheumatoid arthritis. Mediators Inflamm. 2020;3830212. 
16. Damle NK, Klussman K, Leytze G, Myrdal S, Aruffo A, Ledbetter JA, et al. Costimulation of T lymphocytes with integrin ligands intercellular adhesion molecule-1 or vascular cell adhesion molecule-1 induces functional expression of CTLA-4, a second receptor for B7. J Immunol. 1994;152(6):2686-97.

17. Kosmaczewska A, Ciszak L, Boćko D, Frydecka I. Expression and functional significance of CTLA-4, a negative regulator of $T$ cell activation. Arch Immunol Ther Exp (Warsz). 2001;49(1):39-46.

18. Aletaha D, Neogi T, Silman AJ, Funovits J, Felson DT, Bingham CO 3rd, et al. 2010 Rheumatoid arthritis classification criteria: an American College of Rheumatology/European League Against Rheumatism collaborative initiative. Arthritis Rheum. 2010;62(9):2569-81.

19. Steinbrocker O, Traeger CH, Batterman RC. Therapeutic criteria in rheumatoid arthritis. J Am Med Assoc. 1949;140:659-62.

20. Fujita Y, Asano T, Matsuoka N, Temmoku J, Sato S, Matsumoto H, et al. Differential regulation and correlation between g.alectin-9 and anti-CCP antibody (ACPA) in rheumatoid arthritis patients. Arthritis Res Ther. 2020;22(1):80.

21. Matsumoto H, Fujita Y, Asano T, Matsuoka N, Temmoku J, Sato S, et al. T cell immunoglobulin and mucin domain-3 is associated with disease activity and progressive joint damage in rheumatoid arthritis patients. Medicine (Baltimore). 2020;99(44):e22892.

22. BurskaA, Boissinot M, Ponchel Cytokines as biomarkers in rheumatoid arthritis. Mediators Inflamm. 2014:545493.

23. Noack M, Miossec P. Selected cytokine pathways in rheumatoid arthritis. Semin Immunopathol. 2017;39(4):365-383.

24. Möller-Hackbarth K, Dewitz C, Schweigert O, Trad A, Garbers C, Rose-John S, et al. A disintegrin and metalloprotease (ADAM) 10 and ADAM17 are major sheddases of T cell immunoglobulin and mucin domain 3 (Tim-3). J Biol Chem.

2013;288(48):34529-44.

25. Hansen JA, Hanash SM, Tabellini L, Baik C, Lawler RL, Grogan BM, et al. A novel soluble form of Tim-3 associated with severe graft-versus-host disease. Biol Blood Marrow Transplant. 2013;19(9):1323-30.

26. Das M, Zhu C, Kuchroo VK. Tim-3 and its role in regulating anti-tumor immunity. Immunol Rev. 2017;276(1):97-111.

27. Li S, Peng D, He Y, Zhang H, Sun H, Shan S, et al. Expression of TIM-3 on CD4+ and CD8+ T cells in the peripheral blood and synovial fluid of rheumatoid arthritis. APMIS. 2014;122(10):899-904.

28. Liu Y, Shu Q, Gao L, Hou N, Zhao D, Liu X, et al. Increased Tim-3 expression on peripheral lymphocytes from patients with rheumatoid arthritis negatively correlates with disease activity. Clin Immunol. 2010;137(2):288-95.

29. Wiersma VR, Clarke A, Pouwels SD, Perry E, Abdullah TM, Kelly C, et al. Galectin-9 Is a Possible Promoter of Immunopathology in Rheumatoid Arthritis by Activation of Peptidyl Arginine Deiminase 4 (PAD-4) in Granulocytes. Int J Mol Sci. 2019;20(16):4046.

30. Kokkonen H, Söderström I, Rocklöv J, Hallmans G, Lejon K, Rantapää , et al. Up-regulation of cytokines and chemokines predates the onset of rheumatoid arthritis. Arthritis Rheum. 2010;62(2):383-91.

31. Moar P, Tandon R. Galectin-9 as a biomarker of disease severity. Cell Immunol. 2021;361:104287.

32. Moriyama K, Kukita A, Li YJ, Uehara N, Zhang JQ, Takahashi I, et al. Regulation of osteoclastogenesis through Tim-3: possible involvement of the Tim-3/galectin-9 system in the modulation of inflammatory bone destruction. Lab Invest. 2014;94(11):1200-11.

33. Li S, Yu Y, Koehn CD, Zhang Z, Su K. Galectins in the Pathogenesis of Rheumatoid Arthritis. J Clin Cell Immunol. 2013;4(5):1000164.

34. Lee J, Oh JM, Hwang JW, Ahn JK, Bae EK, Won J, et al. Expression of human TIM-3 and its correlation with disease activity in rheumatoid arthritis. Scand J Rheumatol. 2011;40(5):334-40.

35. Lee J, Park EJ, Noh JW, Hwang JW, Bae EK, Ahn JK, et al. Underexpression of TIM-3 and blunted galectin-9-induced apoptosis of CD4+ T cells in rheumatoid arthritis. Inflammation. 2012;35(2):633-7.

36. Kim SN, Lee HJ, Jeon MS, Yi T, Song SU. Galectin-9 is Involved in Immunosuppression Mediated by Human Bone Marrowderived Clonal Mesenchymal Stem Cells. Immune Netw. 2015;15(5):241-51.

\section{Tables}

Page 9/18 
Table 1 Baseline characteristics of 132 Japanese patients with RA

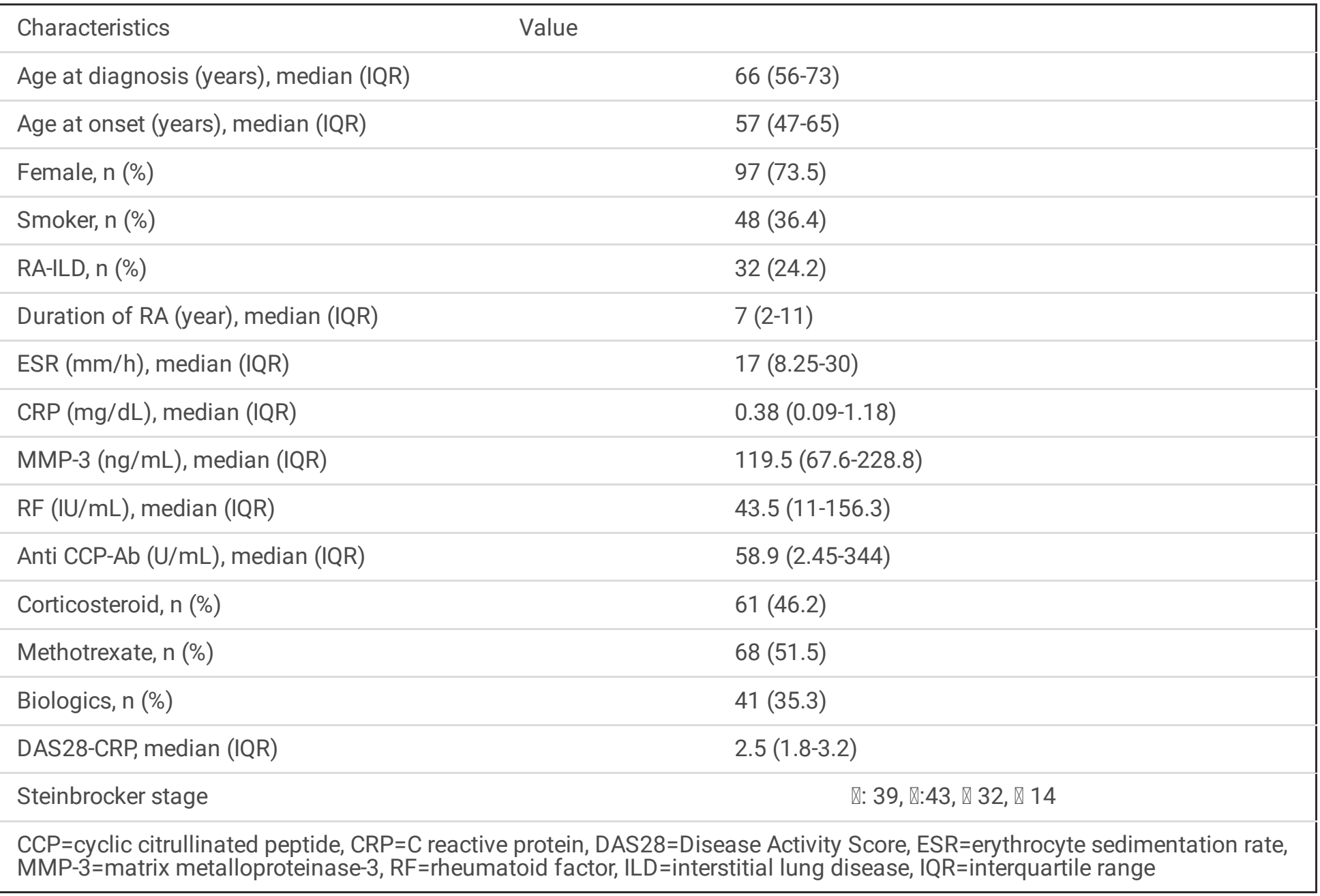

Table 2 shows the correlation of baseline serum levels of cytokines biomarkers.

\begin{tabular}{|c|c|c|c|c|c|c|c|c|c|c|}
\hline & \multicolumn{2}{|l|}{ IL-6 } & \multicolumn{2}{|l|}{ TNF-a } & \multicolumn{2}{|l|}{ Gal-9 } & \multicolumn{2}{|c|}{ sTIM-3 } & \multicolumn{2}{|l|}{ ACPA } \\
\hline & rs & $\begin{array}{l}P \\
\text { value }\end{array}$ & $r s$ & $\begin{array}{l}P \\
\text { value }\end{array}$ & $r s$ & $\begin{array}{l}P \\
\text { value }\end{array}$ & $r s$ & $\begin{array}{l}P \\
\text { value }\end{array}$ & $r s$ & $\begin{array}{l}P \\
\text { value }\end{array}$ \\
\hline IL-6 & - & - & 0.275 & 0.001 & 0.326 & $<0.001$ & 0.281 & 0.001 & -0.044 & 0.620 \\
\hline $\begin{array}{l}\text { TNF- } \\
\mathrm{a}\end{array}$ & 0.275 & 0.001 & - & - & 0.358 & $<0.001$ & 0.215 & 0.015 & 0.029 & 0.744 \\
\hline Gal-9 & 0.326 & $<0.001$ & 0.358 & $<0.001$ & - & - & 0.517 & $<0.001$ & 0.294 & 0.001 \\
\hline $\begin{array}{l}\text { sTIM- } \\
3\end{array}$ & 0.281 & 0.001 & 0.215 & 0.015 & 0.517 & $<0.001$ & - & - & 0.236 & 0.007 \\
\hline ACPA & -0.044 & 0.620 & 0.029 & 0.744 & 0.294 & 0.001 & 0.236 & 0.007 & - & - \\
\hline \multicolumn{11}{|c|}{ The results were obtained using Spearman`s correlation coefficient. } \\
\hline $\begin{array}{l}\text { Abbrev } \\
\text { immun }\end{array}$ & $\begin{array}{l}\text { ons: } \\
\text { obuli }\end{array}$ & $\begin{array}{l}A=a n t i \\
\text { ucin-3 }\end{array}$ & $\begin{array}{l}\text { ed p } \\
\text { mor }\end{array}$ & $\begin{array}{l}\text { le ant } \\
\text { osis } f\end{array}$ & al-9= & ctin-9, & leuki & sTIM- & T cell & \\
\hline
\end{tabular}

\section{Figures}




$$
p<0.001 * *
$$

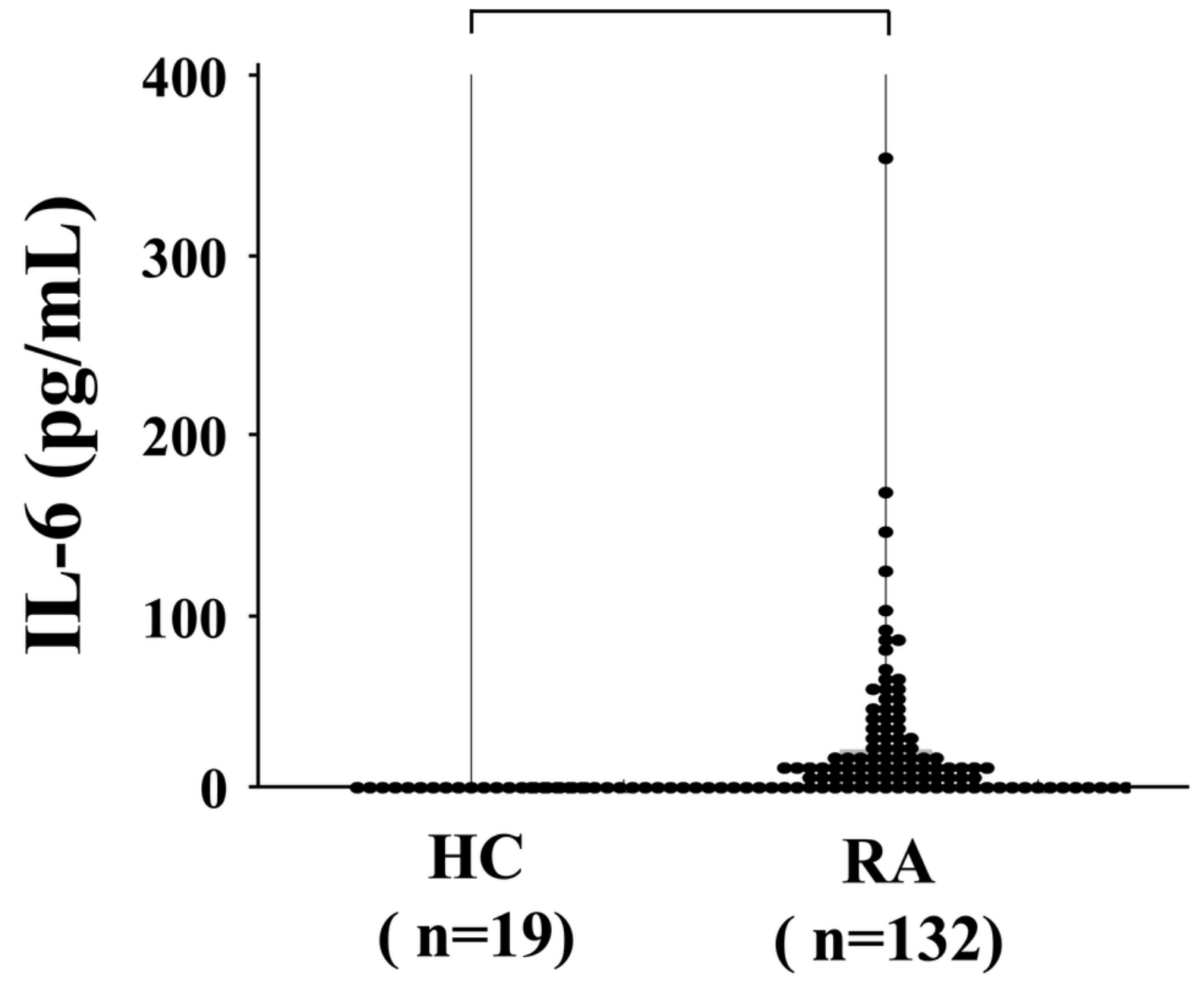

Figure 1

Serum levels of IL-6 among RA patients $(n=132)$ and healthy controls $(H C s, n=19)$. Serum levels of IL-6 in RA patients were significantly higher compared to those in healthy HCs. Statistical significance was determined by Mann-Whitney U test. 


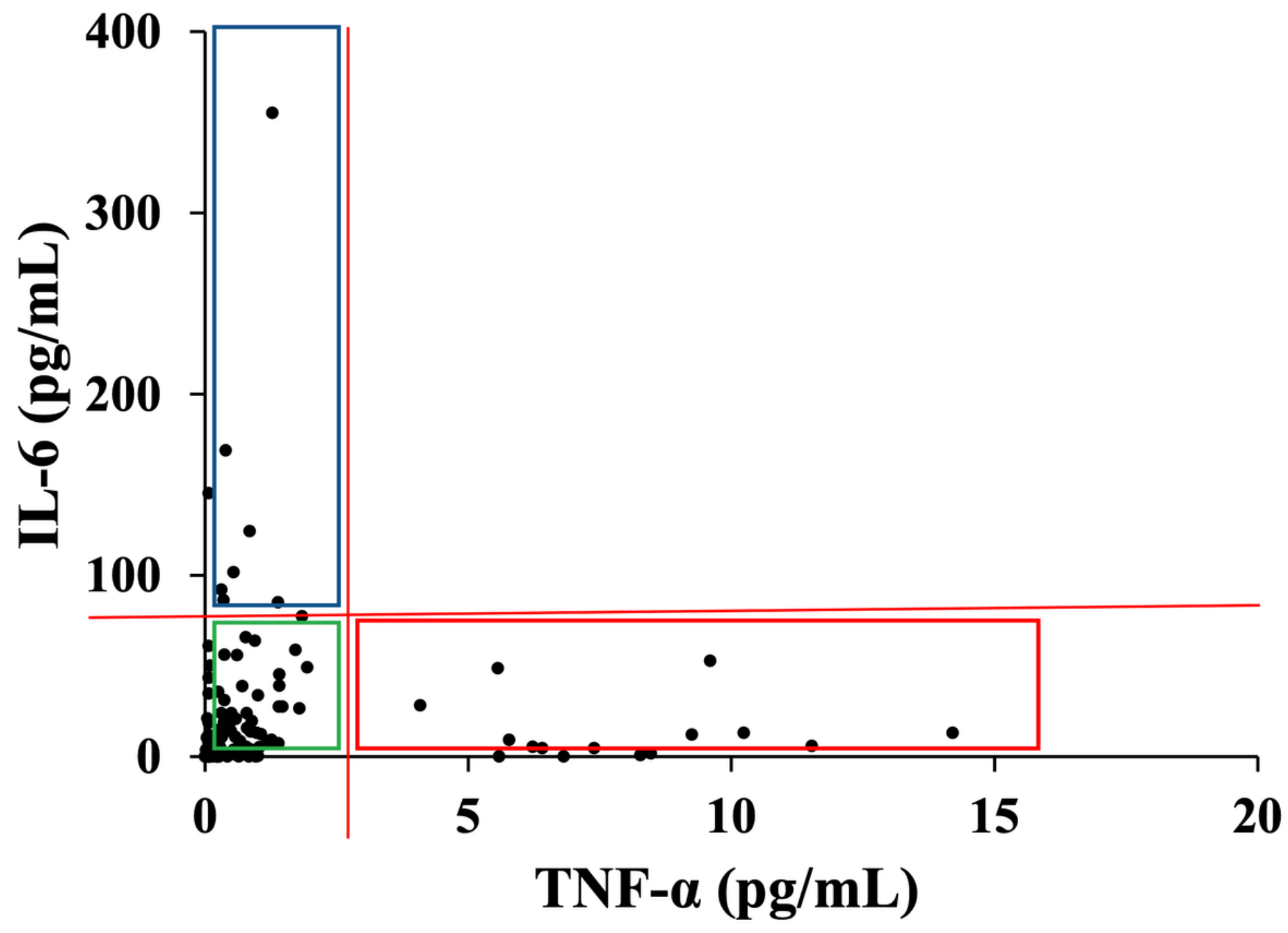

Figure 2

Relationship between serum levels of TNF- $a$ and IL- 6 in RA patients. The serum levels of IL- 6 and TNF- $a$ were elevated independent of each other.
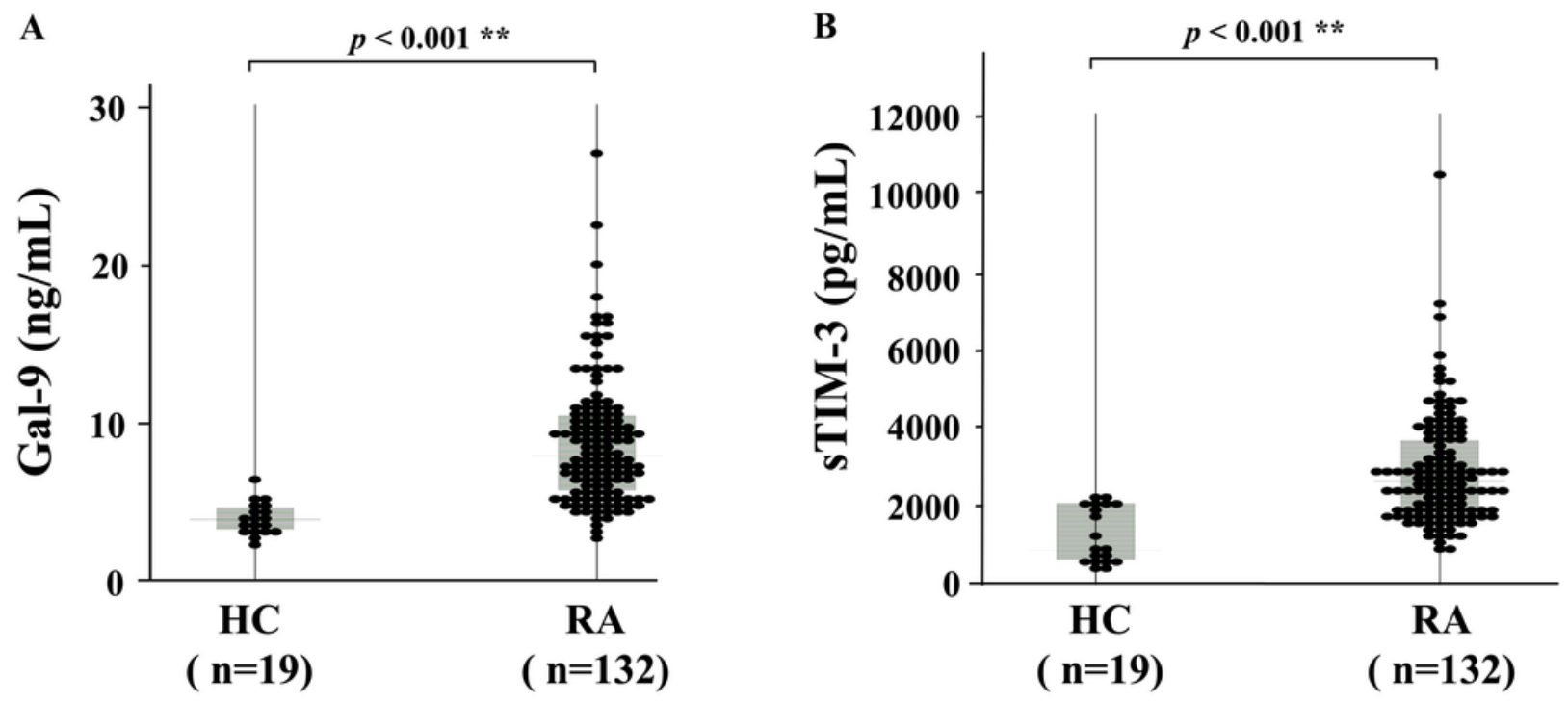

Figure 3 
Serum levels of Gal-9 and sTIM-3 in RA patients $(n=132)$ and HCs $(n=19)$. (A) Serum levels of Gal-9 in RA patients were significantly higher compared to those in HCs. (B) Serum levels of sTIM-3 in RA patients were significantly higher compared to those in HCs. Statistical significance was determined by Mann-Whitney U test.

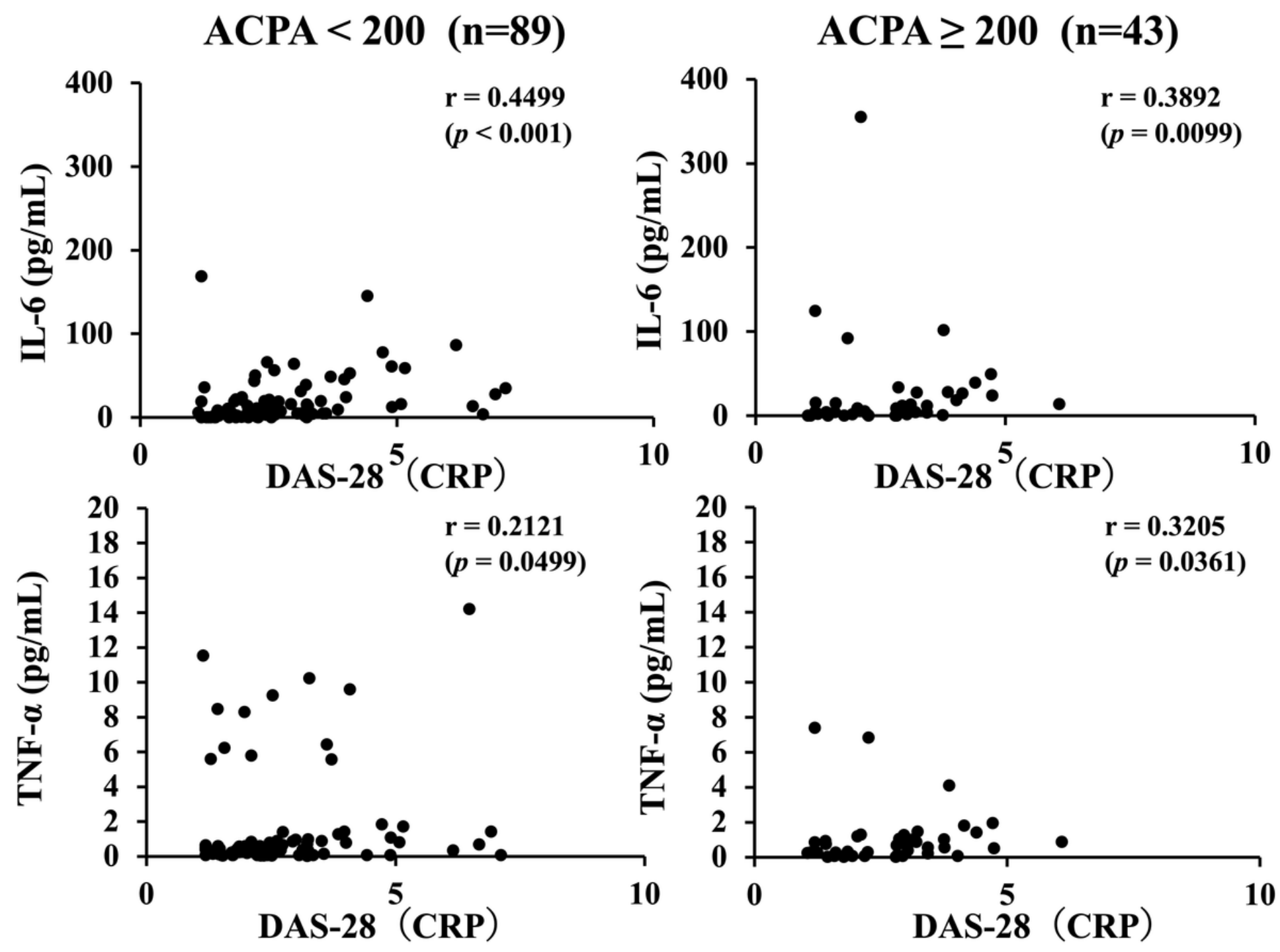

Figure 4

Relationship between serum levels of cytokines (IL-6 or TNF-a) and RA disease activity (DAS28-CRP) in the sub-grouped RA patients according to the titers of ACPA. There were significant correlations between serum levels of cytokines (IL-6 or TNF-a) and RA disease activity (DAS28-CRP), and these correlations were not modulated by the status of ACPA titer $(\geq 200 \mathrm{U} / \mathrm{mL})$. The correlation were determined using Spearman's rank correlation test. 


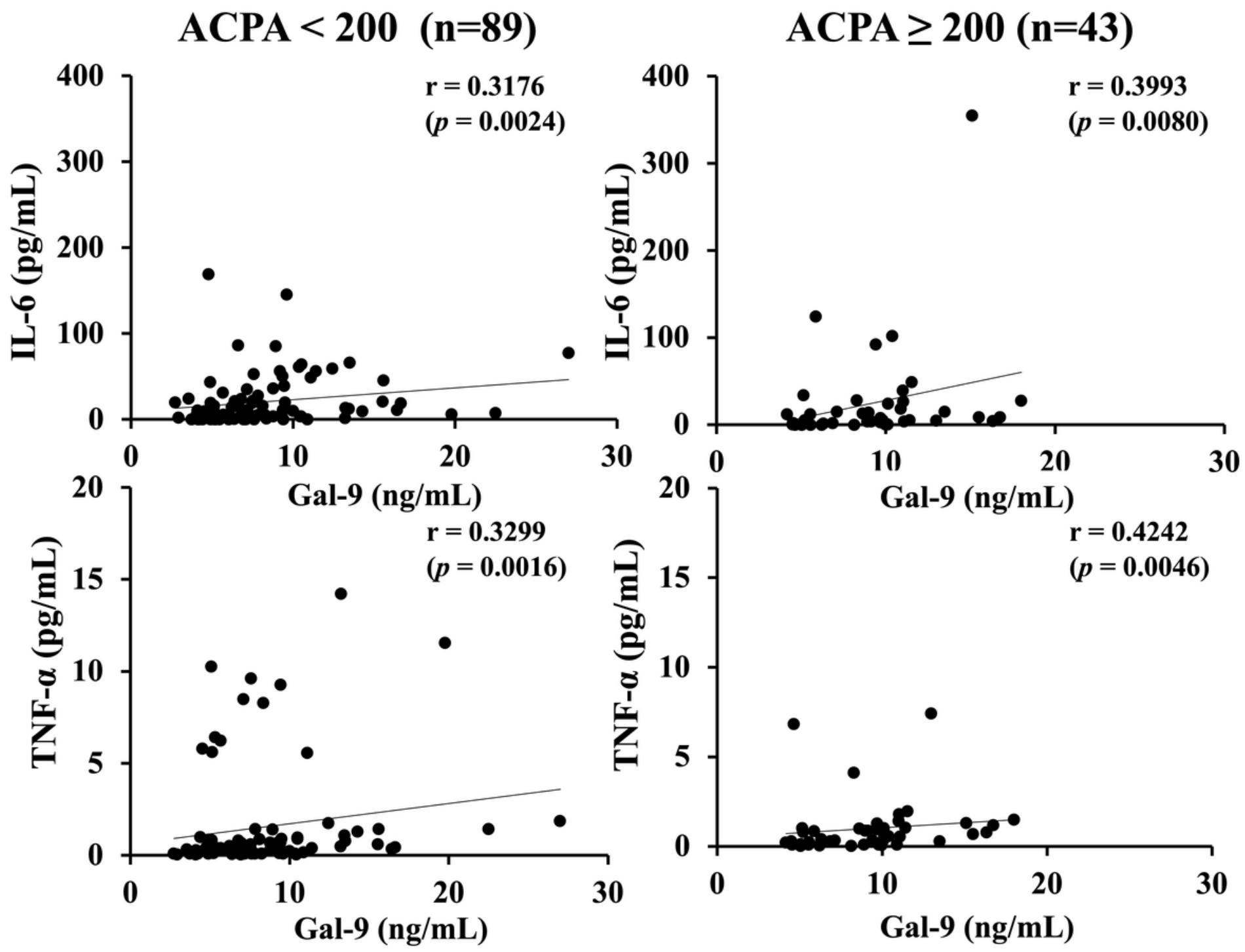

Figure 5

Relationship between serum levels of cytokines (IL- 6 or TNF- $a$ ) and Gal-9 in the sub-grouped RA patients according to the titers of ACPA. There were significant correlations between serum levels of cytokines (IL-6 or TNF-a) and Gal-9, and these correlations were not modulated by the high status of ACPA titers. The correlation were determined using Spearman's rank correlation test. 


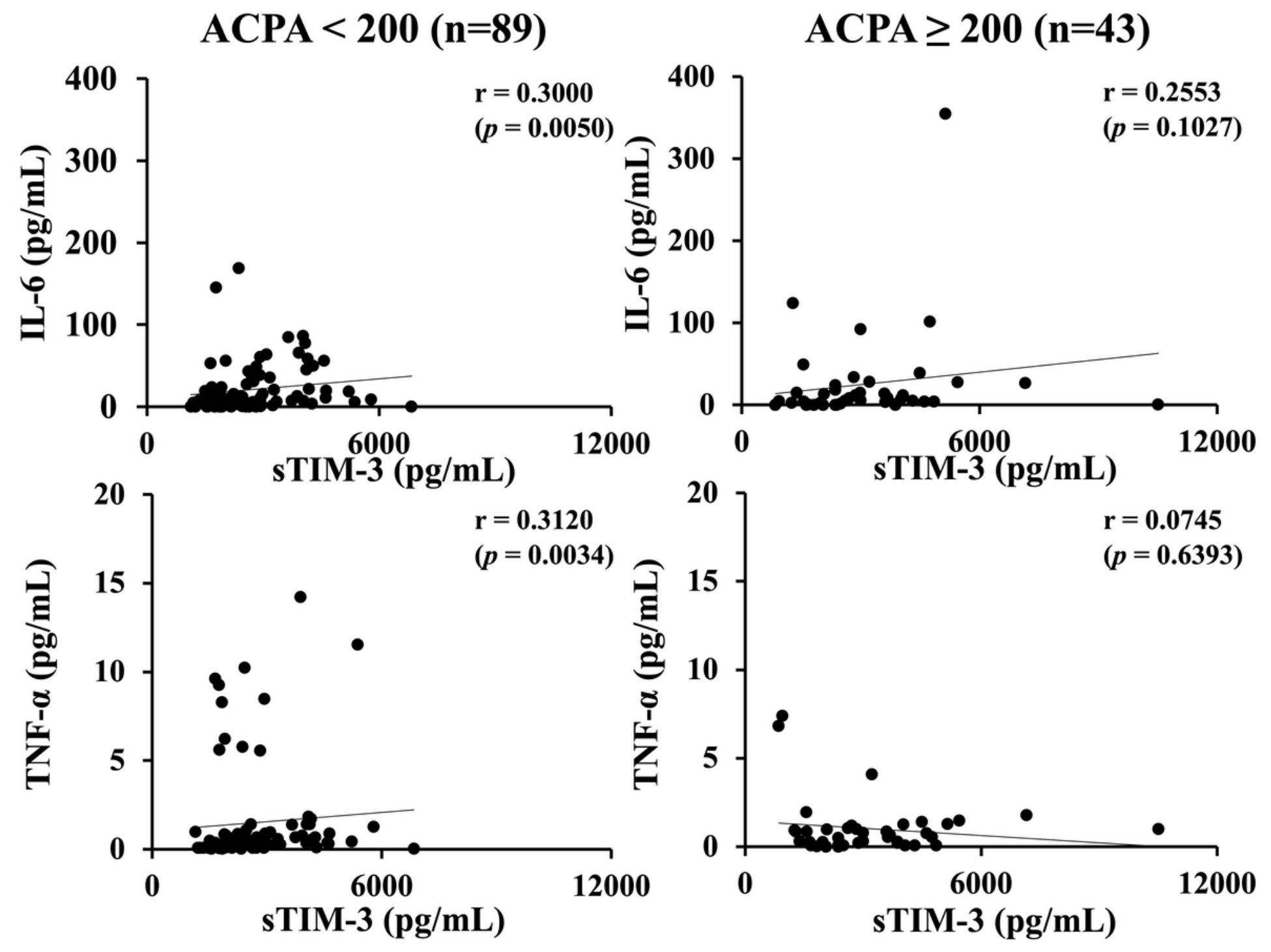

Figure 6

Relationship between serum levels of cytokines (IL- 6 or TNF- $a$ ) and sTIM-3 in the sub-grouped RA patients according to the titers of ACPA. There were significant correlations between serum levels of cytokines (IL- 6 or TNF- $a$ ) and sTIM-3 in RA patients with low-medium levels of ACPA titers $(<200 \mathrm{U} / \mathrm{mL})$. However, there was no significant correlation between serum levels of cytokines (IL-6 or TNF-a) and sTIM-3 in RA patients with high titers of ACPA ( $\geq 200 \mathrm{IU} / \mathrm{mL}$ ). The correlation were determined using Spearman's rank correlation test. 


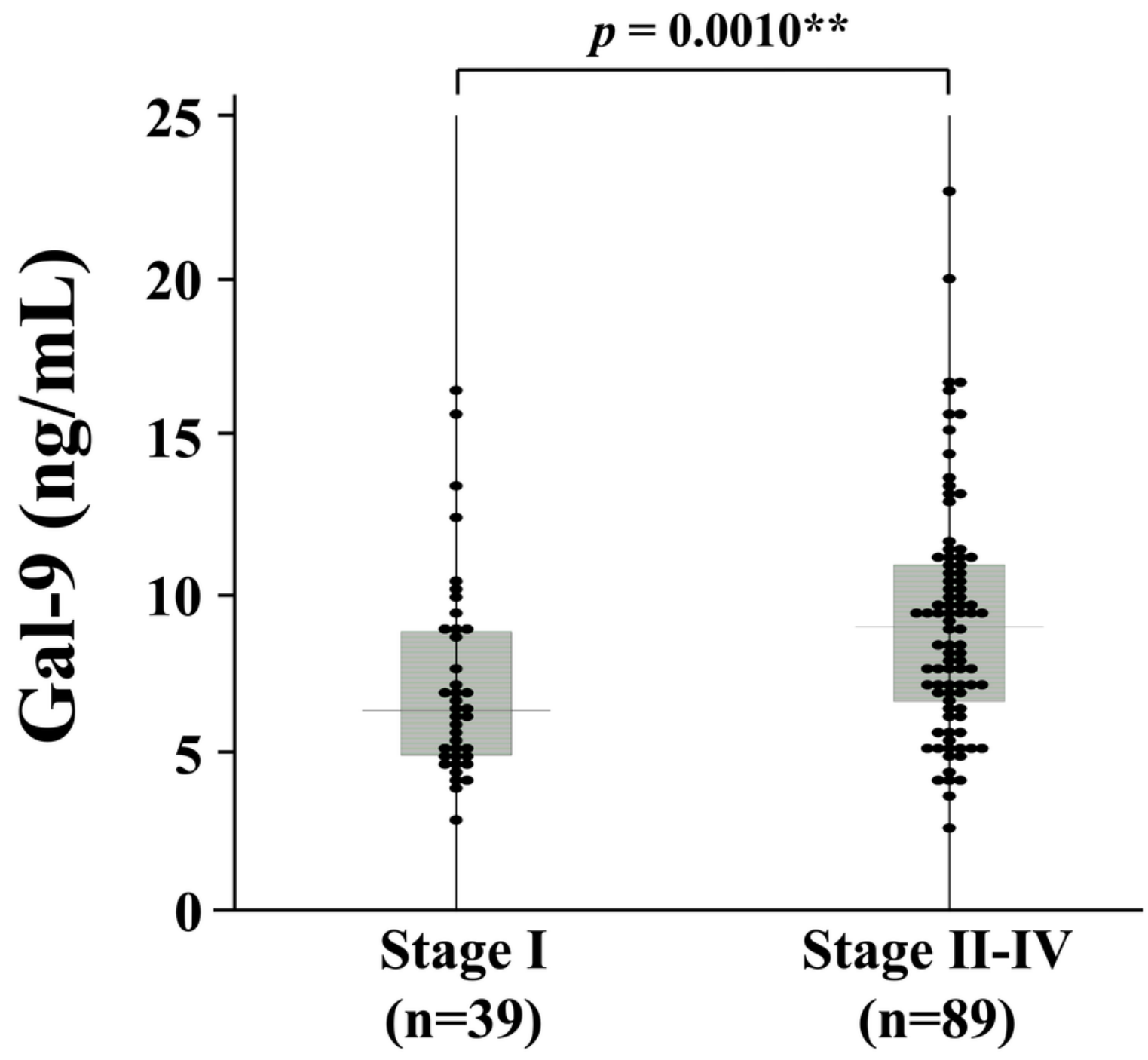

Figure 7

Serum levels of Gal-9 between RA patients ( $n=132)$ with or without advanced joint damage (Stage II-IV). Serum levels of Gal-9 were significantly higher in RA patients with advanced joint damage (stage II-IV) compared to those without advanced joint damage (Stage I). Statistical significance was determined by Mann-Whitney U test.
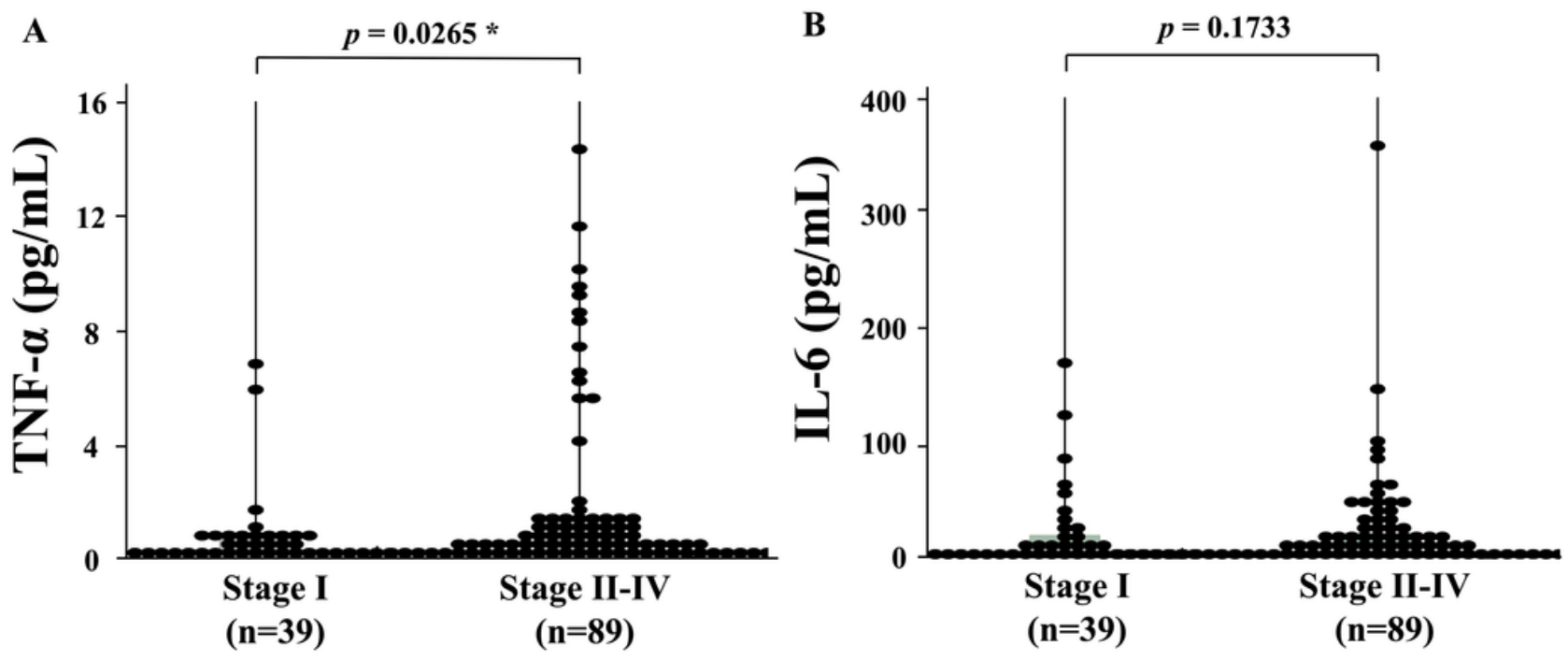
Figure 8

Serum levels of cytokines (IL-6 or TNF-a) in RA patients with or without advanced joint damage. (A) Serum levels of TNF-a in RA patients with advanced joint damage were significantly higher than those in RA patients without advanced joint damage. (B) Serum levels of IL-6 in RA patients with advanced joint damage (Stage II-IV) were higher than those in RA patients without advanced joint damage (Stage I); however, there was no significant difference. Statistical significance was determined by MannWhitney U test.

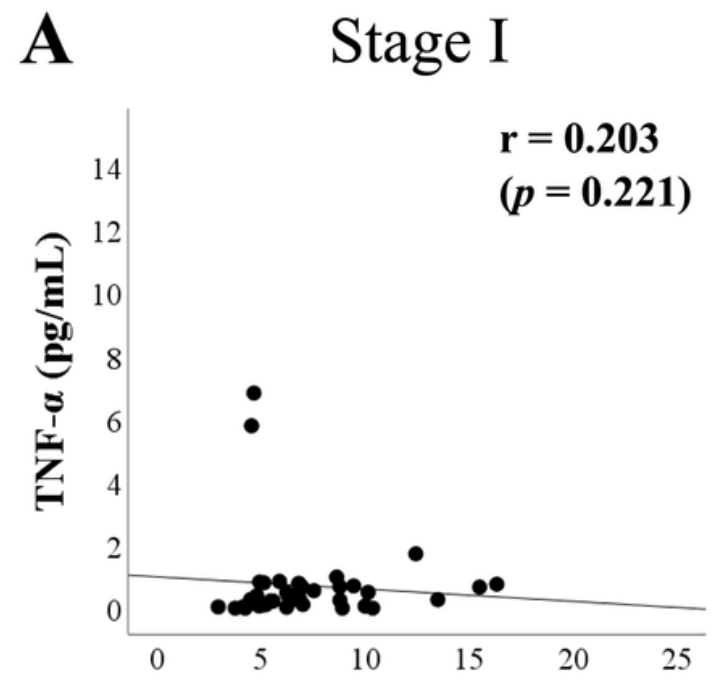

Gal-9 (ng/mL)

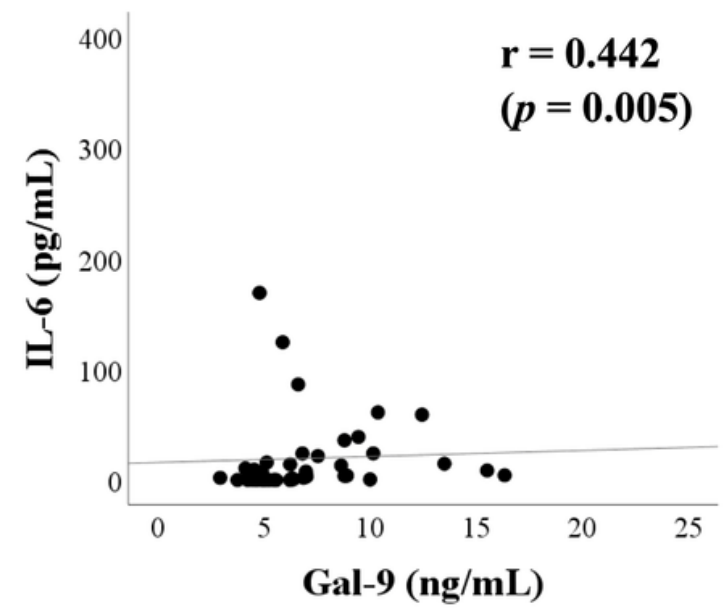

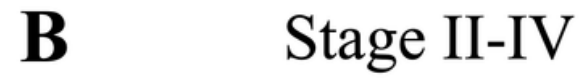

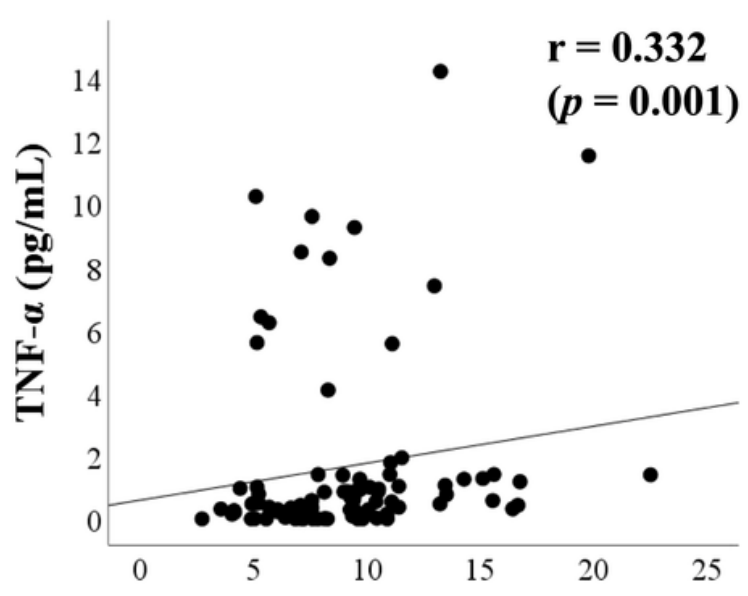

Gal-9 (ng/mL)

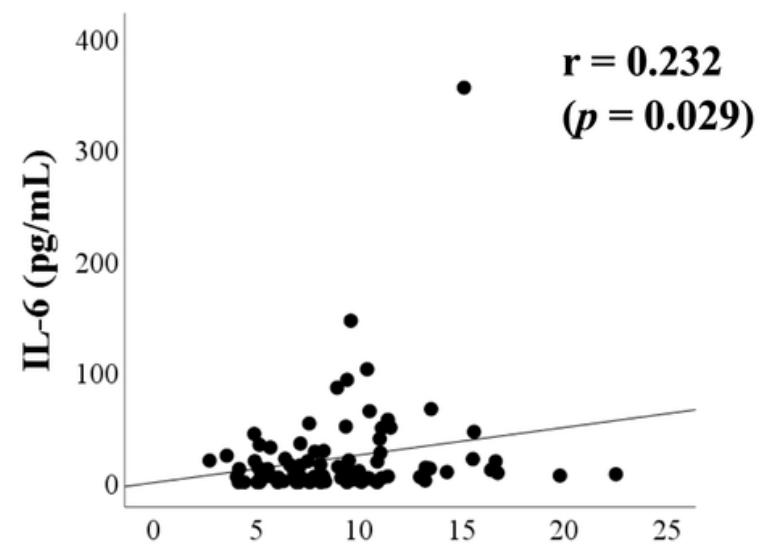

Gal-9 (ng/mL)

\section{Figure 9}

Relationship between serum levels of cytokines (IL-6 or TNF-a) and Gal-9 in RA patients with or without advanced joint damage. (A) There was a significant correlation between IL-6 and Gal-9 in RA patients without advanced joint damage (Stage I). (B) Conversely, there was a significant correlation between TNF- $a$ and Gal-9 in RA patients with advanced rheumatoid joint damage (Stage II-IV). The correlation were determined using Spearman's rank correlation test. 


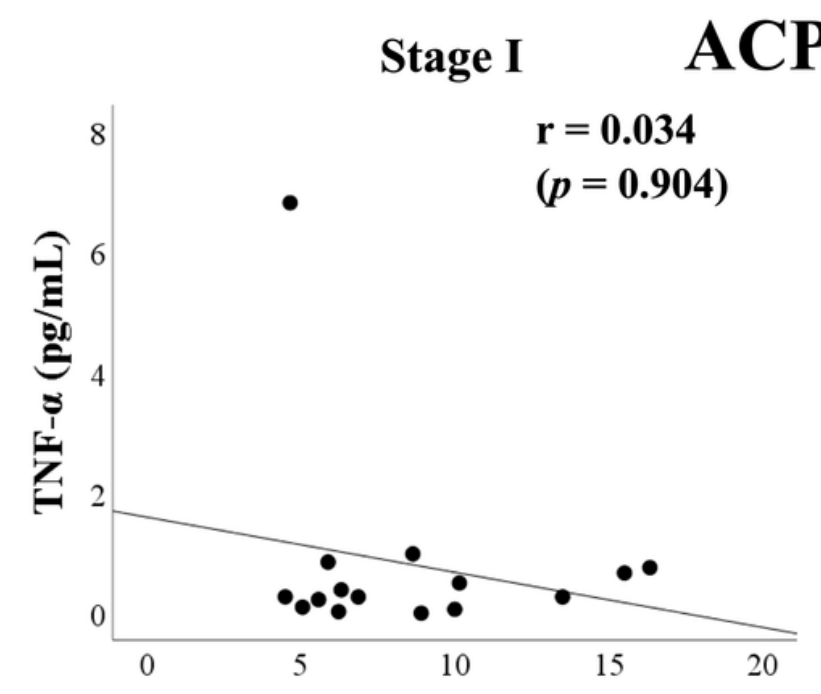

Gal-9 (ng/mL)
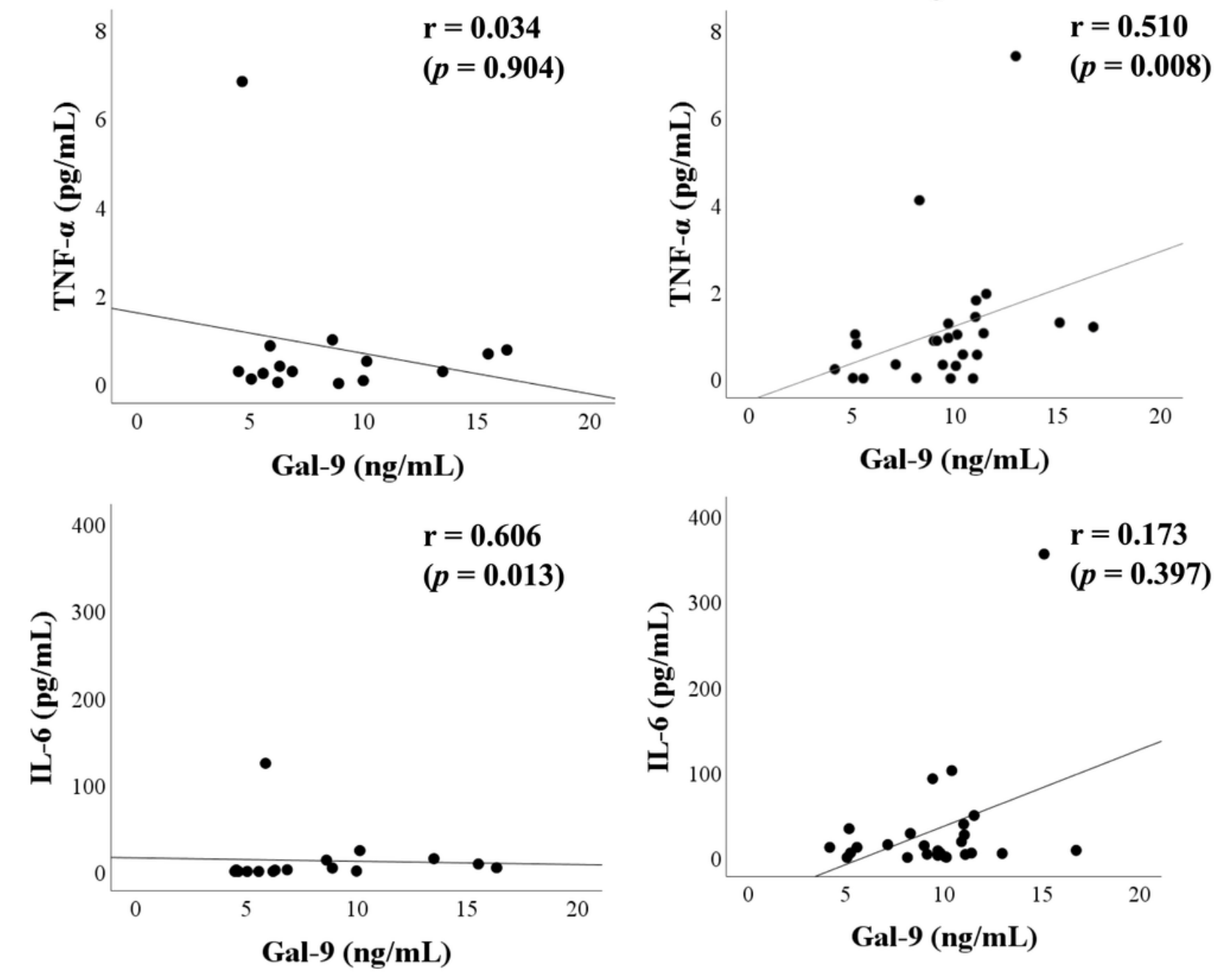

Figure 10

Relationship between serum levels of cytokines (IL- 6 or TNF- - ) and Gal-9 in RA patients with high ACPA titers ( $\geq 200$ IU/mL). (A) There was a significant correlation between IL-6 and Gal-9 in RA patients without advanced joint damage (Stage I). (B) Conversely, there was a significant correlation between TNF- $a$ and Gal-9 in RA patients with advanced rheumatoid joint damage (Stage II-IV). The correlation were determined using Spearman's rank correlation test. 